\title{
Pregnant women's clinical characteristics, intrapartum interventions, and duration of labour in urban China: a multi-center cross- sectional study
}

Chunyi Gu ${ }^{1,2}$, Xiaojiao Wang ${ }^{2}$, Zhijie Zhang ${ }^{3}$, Simone Schwank ${ }^{4}$, Chunxiang Zhu ${ }^{2}$, Zheng Zhang ${ }^{2}$ and Xu Qian ${ }^{1,5^{*}}$

\begin{abstract}
Background: There is an increasing global trend towards the widespread over-medicalisation of labour and childbirth. The present study aimed to investigate pregnant women's clinical characteristics, intrapartum interventions, duration of labour and its associated factors; and to compare the differences of these variables between nulliparas and multiparas in China.

Methods: A multi-center cross-sectional study was carried out in three tertiary hospitals of Fudan University in Shanghai, China. A total of 1523 participants were approched and assessed for eligibility. Data on women's sociodemographic characteristics, intrapartum interventions, and duration of labour were measured and collected. Kaplan-Meier survival analysis was performed to present the curves of total duration of labour by parity. After ztransformation of labour duration, multivariable linear regression was used to control for confounding and to identify independent associations between potential associated factors and the primary outcome of labour duration.

Results: Overall, 1209 eligible women agreed to participate and were investigated. Rates of different intrapartum interventions were $27.4 \%$ in use of amniotomy, 37.9\% in use of oxytocin, $53.0 \%$ in continuous electronic fetal monitoring, and $52.9 \%$ in epidural use, respectively. The curve of total duration of labour was significantly different between nulliparas and multiparas $(P<.001)$. Of the 1209 participants, $983(81.3 \%)$ women eventually achieved successful vaginal birth while $226(18.7 \%)$ women ended in intrapartum caesarean section. The median duration of total stage of labour was significantly longer in the nulliparous group [9.38 $(6.33,14.10)$ hours] than that in the multiparous group $[5.08(3.00,7.83)$ hours] $(P<.001)$. The following factors were independently associated with longer duration of total stage of labour: epidural analgesia $(P<.001)$, primiparity $(P<.001)$, continuous electronic fetal monitoring $(P=.035)$, and increased birth weight $(P=.005)$.

(Continued on next page)
\end{abstract}

\footnotetext{
* Correspondence: xqian@shmu.edu.cn

${ }^{1}$ Department of Maternal, Child and Adolescent Health, School of Public

Health, Fudan University, Shanghai, China

${ }^{5}$ Global Health Institute, Fudan University, Shanghai, China

Full list of author information is available at the end of the article
}

(c) The Author(s). 2020, corrected publication 2020. Open Access This article is licensed under a Creative Commons Attribution 4.0 International License, which permits use, sharing, adaptation, distribution and reproduction in any medium or format, as long as you give appropriate credit to the original author(s) and the source, provide a link to the Creative Commons licence, and indicate if changes were made. The images or other third party material in this article are included in the article's Creative Commons licence, unless indicated otherwise in a credit line to the material. If material is not included in the article's Creative Commons licence and your intended use is not permitted by statutory regulation or exceeds the permitted use, you will need to obtain permission directly from the copyright holder. To view a copy of this licence, visit http://creativecommons.org/ licenses/by/4.0/. The Creative Commons Public Domain Dedication waiver (http://creativecommons.org/publicdomain/zero/1. 0/) applies to the data made available in this article, unless otherwise stated in a credit line to the data. 


\begin{abstract}
(Continued from previous page)
Conclusions: Intrapartum medical interventions become common obstetric practices in urban China. Multifactorial variables independently associated with longer duration of labour were identified, including epidural analgesia, primiparity, continuous electronic fetal monitoring, and increased birth weight. Further research is required to validate these variables and to determine the modifiable factors for labour management. And models of care with lower intervention rates such as midwife-led models of care should be developed and implemented in China.
\end{abstract}

Keywords: Childbirth, Intrapartum intervention, Labour duration, Normal labour

\section{Background}

Childbirth is a normal psychological process for the majority of women. The World Health Organization (WHO) defines normal labour as low risk throughout, spontaneous in onset, with the fetus in vertex position and ending with the mother and fetus in good condition following a spontaneous delivery [1]. Over the decades, however, there is an increasing global trend towards the widespread overmedicalisation of labour and childbirth in many parts of the world [2-4] . A range of labour practices have been applied to initiate, accelerate, terminate, regulate or monitor the physiological process of labour [5], thus leading to a technocratic model of care for normal childbirth with frequent use of interventions during labour and childbirth [6].

Miller et al. termed the excessive medicalisation as too much, too soon (TMTS), which has become a global threat to maternal, fetal, and newborn wellbeing [7]. For instance, rising rates of clinical interventions, such as caesarean section, routine cardiotocography, labour induction, augmentation, and routine episiotomy, have been shown to cause avoidable harm if overused [7-9]. Unnecessary childbirth interventions could be linked to negative consequences in maternal and child health and may cause substantial health-care costs $[10,11]$.

The causes of the rise in intrapartum interventions emerge as a complex multifactorial labyrinth involving health systems, care providers, women, societies, and even fashion and media [12-14]. Many common obstetric practices, however, are of limited or uncertain benefit for low-risk women in spontaneous labour [15]. Unnecessary routine interventions in labour are actually associated with further interventions and result in decreased rates of spontaneous vaginal birth $[16,17]$. Bohren et al. reported that more than a third of women experienced mistreatment and were particularly vulnerable around the time of birth [18]. The increasing medicalisation of childbirth processes tends to undermine the woman's own capability to give birth and negatively impacts her childbirth experience [5]. Satisfaction with women's childbirth experience is related to personal expectations, support from caregivers, bonding with professionals, and women's involvement in decision making $[15,19]$. Hence, there is a growing call from the international community for considering reducing interventional approaches for intrapartum management of childbearing women in spontaneous labour $[15,17]$.

In China, the overall annual rate of caesarean deliveries reached 34.9\% between 2008 and 2014 [20]. In some urban areas like Shanghai, the caesarean section rate declined from $67 \%$ in 2009 to $52 \%$ in 2014 [20], but still far beyond the recommended maximum level of $15 \%$ from the WHO [21]. The third phase of the WHO global survey reported that intrapartum caesarean section (ICS) rate in China accounted for $24.2 \%$ of the women who attempted trial of labour, much higher than that in other countries [22]. For example, it was reported that the ICS rate was $14.6 \%$ in India and $6.9 \%$ in Japan [22]. In Bernitz et al.'s study conducted in Norway, the ICS rate was $5.9 \%$ in the WHO partograph (control) group and 6.8\% in Zhang's guideline (intervention) group [23]. A national explorative study in Dutch reported the ICS variation was $13-15 \%$ for nulliparas and 5-6\% for multiparas, respectively [11]. The above figures show that China is confronted with a more serious situation than other countries in terms of childbirth medicalisation. In addition, since the implementation of China's two-child policy, numbers of women with advanced maternal age and other high risks have increased and posed great challenges on promoting normal labour and childbirth [24, 25].

In view of the substantial changes in women's characteristics and medicalisation of labour management over the decades, Zhang et al. conducted a large contemporary cohort study in US and has established a new labour guideline since then [26]. Within this context, however, data on the characteristics of labour among Chinese women, their use of intrapartum interventions, and the association between women's clinical characteristics and duration of labour are less well investigated. Therefore, the aim of this study was to investigate pregnant women's characteristics, intrapartum interventions, duration of labour and its associated factors; and to compare the differences of these variables between nulliparas and multiparas in urban China.

\section{Methods}

\section{Settings}

A multi-center cross-sectional observational study was carried out in three tertiary university hospitals in urban 
China between 1 August 2018 and 31 January 2019. The three hospitals included Obstetrics and Gynecology Hospital, Pudong Hospital, and Huashan Hospital North, which were all affiliated to Fudan University. Maternity health care in these hospitals (also in whole China) share a similar obstetrician-led model. Chinese obstetricians provide antenatal, intrapartum, and postnatal care for pregnant women throughout their perinatal periods, while the midwives only work in labour and delivery units. Most of the midwives working there are nurses learning on the job. They need to follow obstetricians' orders to deliver intrapartum care.

\section{Participants}

The inclusion criteria of our study were as follows: (1) healthy women at term (37-41.6 gestational weeks); (2) singleton, vertex presentation; (3) with spontaneous onset of labour; and (4) with no maternal or fetal risk factors. The exclusion criteria of women recruitment were: (1) body mass index (BMI) $\geq 30 \mathrm{~kg} / \mathrm{m}^{2}$ before pregnancy; (2) trial of labour after previous caesarean delivery; (3) presence of indications of caesarean section; and (4) with complications such as heart disease, hypertension, and gestational diabetes mellitus requiring control by medication.

Sample size was calculated using the sample size formula for a cross-sectional study $\left[n=\left(Z_{\alpha / 2}^{2} p q\right) / \delta^{2}\right]$ [27]. In this formula, (1) $n$ represents the sample size; (2) $p$ represents ICS rate; (3) $q$ equals to (1-p); (4) $Z_{\alpha / 2}$ equals to 1.96 with $\alpha$ valued as 0.05 and by a two-tailed test; and (5) $\delta$ represents an allowable error and equals to $0.1 p$. Considering $24.2 \%$ proportion of ICS in China reported in the WHO global survey [22], we required 1203 participants in the study as the final sample size.

A total of 1523 women were approached and assessed for eligibility during the study period when they were admitted to the labour and delivery unit. Then 1258 women met the inclusion criteria and 49 women declined to participate. The rate of all eligible women was 82.6\% (1258/1523). Finally 1209 women were recruited in our study (Fig. 1). There were no significant differences in basic characteristics between eligible women who agreed to participate and those who declined to participate $(P>0.05)$.

\section{Instrument}

A tailored structured questionnaire (Additional file 1) was used to measure and describe women's clinical characteristics, intrapartum interventions, and duration of labour. It was comprised of four parts including women's baseline information, maternal conditions at admission of labour and delivery unit, labour progress and intrapartum interventions, and neonatal outcomes.
The questionnaire was pre-tested in a similar population to the three study hospitals. Minor revisions of the questionnaire were made after the pretest.

\section{Data collection}

Data were collected from women at the onset of labour. These women were followed until completion of delivering the baby. The onset of labour in this study was defined as regular, painful uterine contractions resulting in progressive cervical effacement and dilation [28, 29]. Labour was divided into three stages: first stage (including latent phase and active phase), second stage, and third stage. The sum of the three stages was equal to the total stage of labour.

The three research hospitals received a package of questionnaires along with invitation letters, consent forms and envelopes to ensure confidentiality of study participants. Ten midwives in labour and delivery units of the three hospitals were trained to be investigators of the study and filled in the questionnaires correctly. Data on maternal sociodemographic and clinical characteristics were obtained via chart review and inquiry from the consented women. Concurrently, four research nursemidwives were recruited and trained to supervise and assist investigators, collect questionnaires, and check for consistencies and completeness of filled questionnaires. Envelopes with completed questionnaires were sent back directly to the research team. Questionnaires with any problems were returned to the investigators for resurvey.

The main outcomes for analysis were durations of labour including the first, second and total stages of labour. Other variables were women's sociodemographic characteristics, use of intrapartum interventions, and birth outcomes.

\section{Data analysis}

Body mass index (BMI) was calculated and classified as underweight $\left(\mathrm{BMI}<18.5 \mathrm{~kg} / \mathrm{m}^{2}\right)$, normal weight (BMI between 18.5 and $24.9 \mathrm{~kg} / \mathrm{m}^{2}$ ), overweight (BMI between 25.0 and $\left.29.9 \mathrm{~kg} / \mathrm{m}^{2}\right)$, or obese $\left(\mathrm{BMI} \geq 30.0 \mathrm{~kg} / \mathrm{m}^{2}\right)$ [30]. Participants were grouped into adequate gestational weight gain (GWG), inadequate GWG, and excessive GWG (Table 1).

Descriptive statistics were calculated for sociodemographic and clinical characteristics of participants, which were summarized according to the following factors: age, educational level, household monthly income per capita, gestational weeks, prepregnancy weight category, gestational weight gain, intrapartum interventions, and labour duration. Continuous variables were analysed by means (SD) or by median $\left(\mathrm{P}_{25}, \mathrm{P}_{75}\right)$. Categorical variables were analysed by number and frequency. For continuous variables, the statistical significance of the association 


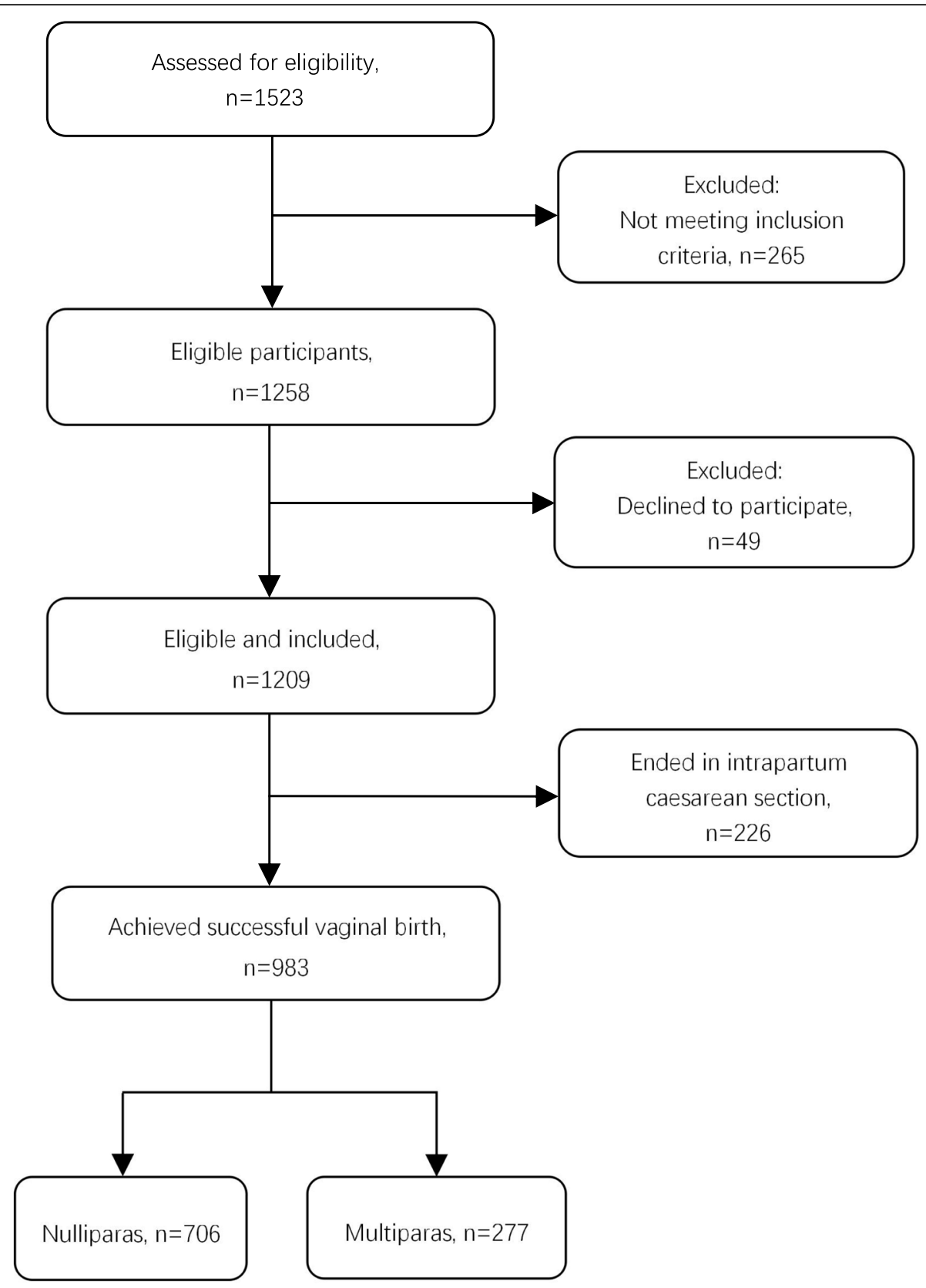

Fig. 1 Flow chart of included and excluded participants

between these factors and parities was tested using the t-test and Mann Whitney-U test. For categorical variables, the statistical significance of the association was tested using Chi-square test.

Kaplan-Meier survival analysis was performed to estimate the time-to-event outcome (vaginal birth). Logrank test was used to compare the curves of total duration of labour between nulliparas and multiparas. Multivariable linear regression analysis was performed to explore the association between explanatory variables and the dependent variable (duration of labour), and to identify the relative importance of each independent variable to the outcome variable by controlling for the effects of other variables. Z-transformation was used to transform the non-normally distributed variable (duration of total stage of labour) into a normally distributed variable ( $\mathrm{N}$ score of the duration of total stage of labour) using Blom's Formula. The collected data were entered to Epidata Info and then exported to Statistical Package for Social Sciences (SPSS) Statistics Version 22.0. Statistical significance was set at a $p$ value $<0.05$. 
Table 1 Category of gestational weight gain

\begin{tabular}{|c|c|c|}
\hline \multicolumn{3}{|c|}{ Underweight $\left(\mathrm{BMI}<18.5 \mathrm{~kg} / \mathrm{m}^{2}\right)$} \\
\hline$I G W G^{a}(1)$ & $A G W G^{\mathrm{b}}(2)$ & EGWG (3) \\
\hline$<12.7 \mathrm{~kg}$ & $12.7 \sim 18.1 \mathrm{~kg}$ & $>18.1 \mathrm{~kg}$ \\
\hline \multicolumn{3}{|c|}{ Normal weight (BMI $18.5-24.9 \mathrm{~kg} / \mathrm{m}^{2}$ ) } \\
\hline $\operatorname{IGWG}^{\mathrm{a}}(4)$ & $\mathrm{AGWG}^{\mathrm{b}}(5)$ & $\mathrm{EGWG}^{\mathrm{c}}(6)$ \\
\hline$<11.3 \mathrm{~kg}$ & $11.3 \sim 15.9 \mathrm{~kg}$ & $>15.9 \mathrm{~kg}$ \\
\hline \multicolumn{3}{|c|}{ Overweight (BMI $25.0-29.9 \mathrm{~kg} / \mathrm{m}^{2}$ ) } \\
\hline$I_{G W G}^{a}(7)$ & $A G W G^{b}(8)$ & $\mathrm{EGWG}^{\mathrm{c}}(9)$ \\
\hline$<6.8 \mathrm{~kg}$ & $6.8 \sim 11.3 \mathrm{~kg}$ & $>11.3 \mathrm{~kg}$ \\
\hline \multicolumn{3}{|c|}{ Obese $\left(\mathrm{BMI} \geq 30.0 \mathrm{~kg} / \mathrm{m}^{2}\right)$} \\
\hline$I_{G W G}(10)$ & $\mathrm{AGWG}^{\mathrm{b}}(11)$ & $\mathrm{EGWG}^{\mathrm{C}}(12)$ \\
\hline$<5.0 \mathrm{~kg}$ & $5.0 \sim 9.1 \mathrm{~kg}$ & $>9.1 \mathrm{~kg}$ \\
\hline
\end{tabular}

a IGWG Inadequate gestational weight gain (1)(4)(7)(10);

${ }^{b}$ AGWG Adequate gestational weight gain (2)(5)(8)(11);

${ }^{c}$ EGWG Excessive gestational weight gain (3)(6)(9)(12)

\section{Results}

A total of 1523 women admitted to the labour and delivery unit were approached and assessed for their eligibility and consent for the study, and 1209 participants provided informed consent. The sociodemographic characteristics of the study population are presented in Table 2. Of the 1209 consented participants, 841 (69.6\%) women were nulliparous and 368 (30.4\%) were multiparous women. The participants' ages ranged from 20 to 48 years, with the mean maternal age of 29.86 (SD3.94) years. The majority of the participants were well educated, with $65.9 \%(n=797)$ having completed a college or higher level degree. The mean gestational week at admission of this study was 39.56 (SD1.02) weeks, ranging from 37.0 to 41.5 weeks. The overall prevalence of underweight women was $18.9 \%(n=228)$, whereas overweight and obesity accounted for $12.2 \%(n=147)$.

Different intrapartum interventions were performed for the labouring women, including $27.4 \%(n=331)$ of the amniotomy, $37.9 \%(n=458)$ of use of oxytocin,

Table $\mathbf{2}$ Characteristics of the participants by parity

\begin{tabular}{|c|c|c|c|c|c|}
\hline Characteristics & Total $(N=1209)$ & Nullipara $(n=841)$ & Multipara $(n=368)$ & Statistic & $P$ value \\
\hline Age (years), n (\%) & & & & $191.721^{\mathrm{a}}$ & $<.001$ \\
\hline $20-24 y$ & $78(6.5)$ & $57(6.8)$ & $21(5.7)$ & & \\
\hline $25-29 y$ & $533(44.1)$ & $462(54.9)$ & $71(19.3)$ & & \\
\hline $30-34 y$ & $456(37.7)$ & $276(32.8)$ & $180(48.9)$ & & \\
\hline $35-39 y$ & $119(9.8)$ & $44(5.2)$ & $75(20.4)$ & & \\
\hline$\geq 40 y$ & $23(1.9)$ & $2(0.2)$ & $21(5.7)$ & & \\
\hline Educational level, n (\%) & & & & $9.067^{\mathrm{a}}$ & 0.028 \\
\hline Junior high school or below & $162(13.4)$ & $102(12.1)$ & $60(16.3)$ & & \\
\hline Senior high/ technical school & $250(20.7)$ & $169(20.1)$ & $81(22.0)$ & & \\
\hline College graduate & $597(49.4)$ & $438(52.1)$ & $159(43.2)$ & & \\
\hline Postgraduate & $200(16.5)$ & $132(15.7)$ & $68(18.5)$ & & \\
\hline Household monthly income per capita, CNY, n (\%) & & & & $0.605^{\mathrm{a}}$ & 0.895 \\
\hline$<5000$ & $95(7.9)$ & $69(8.2)$ & $26(7.1)$ & & \\
\hline $5000-7999$ & $239(19.8)$ & $168(20.0)$ & $71(19.3)$ & & \\
\hline $8000-10,000$ & $279(23.1)$ & $193(22.9)$ & $86(23.4)$ & & \\
\hline$>10,000$ & $596(49.3)$ & $411(48.9)$ & $185(50.3)$ & & \\
\hline Gestational weeks, mean (SD) & $39.56(1.02)$ & $39.66(1.02)$ & $39.34(1.01)$ & $5.159^{\mathrm{b}}$ & 0.762 \\
\hline Prepregnancy weight category, $\mathrm{n}(\%)$ & & & & $7.536^{\mathrm{a}}$ & 0.057 \\
\hline Underweight (BMl < 18.5 kg/m²) & $226(18.7)$ & $146(17.4)$ & $80(21.7)$ & & \\
\hline Normal weight (BMI $18.5-24.9 \mathrm{~kg} / \mathrm{m}^{2}$ ) & $875(72.4)$ & $613(72.9)$ & $262(71.2)$ & & \\
\hline Overweight (BMI 25.0-29.9 kg/m²) & $100(8.3)$ & $78(9.3)$ & $22(6.0)$ & & \\
\hline Obese $\left(B M I \geq 30.0 \mathrm{~kg} / \mathrm{m}^{2}\right)$ & $8(0.7)$ & $4(0.5)$ & $4(1.1)$ & & \\
\hline GWG, n (\%) & & & & $6.665^{\mathrm{a}}$ & 0.036 \\
\hline Inadequate GWG $(1)(4)(7)(10)^{c}$ & $254(21.0)$ & $175(20.8)$ & $79(21.5)$ & & \\
\hline Adequate GWG (2)(5)(8)(11) & $589(48.7)$ & $393(46.7)$ & $196(53.3)$ & & \\
\hline Excessive GWG (3)(6)(9)(12) ${ }^{c}$ & $366(30.3)$ & $273(32.5)$ & $93(25.3)$ & & \\
\hline
\end{tabular}

CNY Chinese Yuan; BMI Body mass index; GWG Gestational weight gain

${ }^{\text {a }}$ Chi-square test; ${ }^{b} t$ test;

${ }^{c}$ Numbers in parentheses indicate number for category of gestational weight gain listed in Table 1 
$53.0 \%(n=641)$ of the continuous electronic fetal monitoring (EFM), and $52.9 \%(n=639)$ of use of epidural analgesia (Table 3). Of the 1209 participants, 983 women eventually achieved successful vaginal birth after trial of labour while 226 (18.7\%) women ended in an ICS. These women undergoing ICS were censored during labour observation. Kaplan-Meier survival analysis unfolded that the duration of total stage of labour was significantly longer in nulliparous group than that in multiparous group $\left(\chi^{2}=81.805, P<.001\right)$ (Fig. 2$)$.

Of the 983 participating women who delivered vaginally, 706 women were nulliparous and 277 women were multiparous. The median duration of first stage of labour was $8.50(5.50,13.00)$ hours in the nulliparous group, and $4.50(2.58,7.00)$ hours in the multiparous group, making significant differences between the two groups $(P<0.001)$. The median duration of second stage of labour in the nulliparous group $[0.78(0.45,1.18)$ hours] was significantly longer than that in the multiparous group $[0.28(0.16,0.53)$ hour $](P<0.001)$. The median duration of total stage of labour was 9.38 (6.33, 14.10) hours in the nulliparous group, and 5.08 (3.00,
7.83) hours in the multiparous group, giving significant differences between the two groups $(P<0.001)$. We found no significant differences in the neonatal birth weight between the two groups $(P>0.05)$ (Table 3$)$.

Compared with nulliparous women, multiparous women in this study were less likely to have an amniotomy (75 [20.4\%] versus 256 [30.4\%]; $P<.001)$, less likely to be administered oxytocin (67 [18.2\%] versus 391 [46.5\%]; $P<.001)$, less likely to receive continuous EFM (119 [32.3\%] versus 522 [62.1\%]; $P<.001)$, and less likely to use epidural analgesia (101 [27.4\%] versus 538 [64.0\%]; $P<.001)$ (Table 3).

Of the 983 women who eventually achieved successful vaginal birth after trial of labour, we analysed the associations between potential predictors and the outcome variable of labour duration. Due to skewness of the distribution of labour duration, data was z-transformed into normal distribution before analysed using multivariable linear regression. The potential associated factors were then entered into the multivariable linear regression model. In the final model, the following factors were independently associated with longer duration of total

Table 3 Intrapartum interventions, birth outcomes and duration of labour

\begin{tabular}{|c|c|c|c|c|c|}
\hline Variables & Total $(N=1209)$ & Nullipara $(n=841)$ & Multipara $(n=368)$ & Statistic & $P$ value \\
\hline \multicolumn{6}{|l|}{ Amniotomy, n (\%) } \\
\hline Yes & $331(27.4)$ & $256(30.4)$ & $75(20.4)$ & \multirow[t]{2}{*}{$13.029^{b}$} & \multirow[t]{2}{*}{$<.001$} \\
\hline No & 878 (72.6) & $585(69.6)$ & $293(79.6)$ & & \\
\hline \multicolumn{6}{|l|}{ Use of oxytocin, n (\%) } \\
\hline Yes & $458(37.9)$ & $391(46.5)$ & $67(18.2)$ & \multirow[t]{2}{*}{$87.036^{\mathrm{b}}$} & \multirow[t]{2}{*}{$<.001$} \\
\hline No & $751(62.1)$ & $450(53.5)$ & $301(81.8)$ & & \\
\hline \multicolumn{6}{|l|}{ Continuous EFM, n (\%) } \\
\hline Yes & $641(53.0)$ & $522(62.1)$ & $119(32.3)$ & \multirow[t]{2}{*}{$90.847^{b}$} & \multirow[t]{2}{*}{$<.001$} \\
\hline No & $568(47.0)$ & $319(37.9)$ & $249(67.7)$ & & \\
\hline \multicolumn{6}{|l|}{ Epidural analgesia, n (\%) } \\
\hline Yes & $639(52.9)$ & $538(64.0)$ & $101(27.4)$ & \multirow[t]{2}{*}{$137.055^{b}$} & \multirow[t]{2}{*}{$<.001$} \\
\hline No & $570(47.1)$ & $303(36.0)$ & $267(72.6)$ & & \\
\hline \multicolumn{6}{|l|}{ Mode of delivery, n (\%) } \\
\hline Vaginal birth & $983(81.3)$ & $706(83.9)$ & $277(75.3)$ & \multirow[t]{2}{*}{$12.678^{b}$} & \multirow[t]{2}{*}{$<.001$} \\
\hline ICS & $226(18.7)$ & $135(16.1)$ & $91(24.7)$ & & \\
\hline \multicolumn{6}{|l|}{ Neonatal birth weight, n (\%) } \\
\hline$<2500 \mathrm{~g}$ & $193(16.0)$ & $150(17.8)$ & $43(11.7)$ & \multirow[t]{3}{*}{$2.308^{b}$} & \multirow[t]{3}{*}{0.315} \\
\hline $2500-4000 \mathrm{~g}$ & $959(79.3)$ & $654(77.8)$ & $305(82.9)$ & & \\
\hline$>4000 \mathrm{~g}$ & $57(4.7)$ & $37(4.4)$ & $20(5.4)$ & & \\
\hline Duration of 1 st SOL $(706 / 277)^{a}$, median $\left(P_{25}, P_{75}\right)$ & $7.00(4.00,11.00)$ & $8.50(5.50,13.00)$ & $4.50(2.587 .00)$ & $50,391.000^{c}$ & $<.001$ \\
\hline Duration of 2nd SOL $(706 / 277)^{a}$, median $\left(P_{25}, P_{75}\right)$ & $0.63(0.32,1.07)$ & $0.78(0.45,1.18)$ & $0.28(0.16,0.53)$ & $42,825.000^{c}$ & $<.001$ \\
\hline Duration of total SOL $(706 / 277)^{a}$, median $\left(P_{25}, P_{75}\right)$ & $8.00(4.83,12.25)$ & $9.38(6.33,14.10)$ & $5.08(3.00,7.83)$ & $46,859.500^{c}$ & $<.001$ \\
\hline
\end{tabular}

EFM Electronic fetal monitoring; ICS Intrapartum cesarean section; SOL Stage of labour

${ }^{a}$ Numbers in parentheses indicate number for whom this information was available (nullipara/multipara); ${ }^{\text {b }}$ Chi-square test; ${ }^{\mathrm{c}}$ Mann-Whitney $\mathrm{U}$ test 


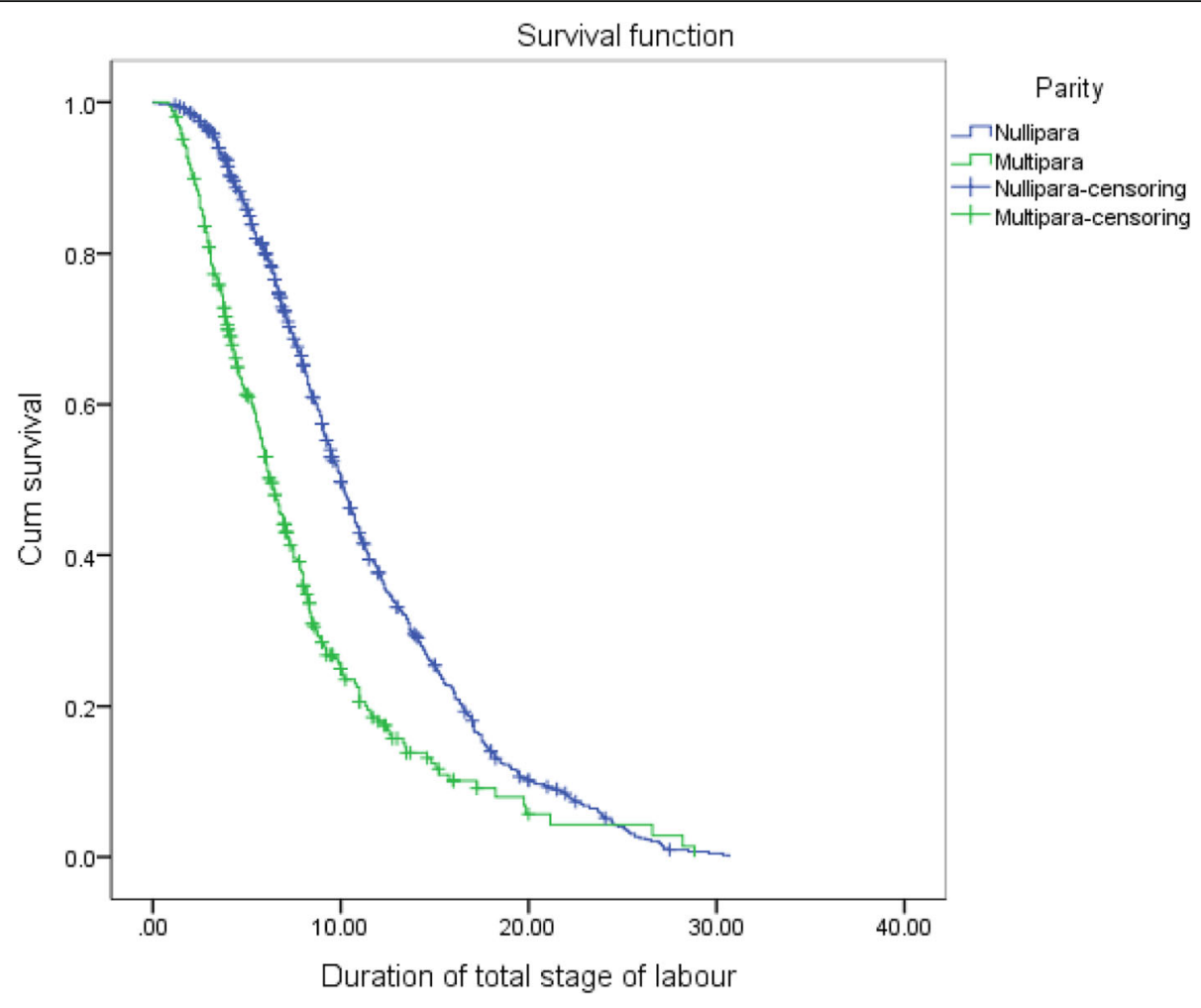

Fig. 2 Duration of total stage of labour by parity $(n=1209)$

stage of labour: epidural analgesia $(P<.001)$, primiparity $(P<.001)$, continuous EFM $(P=.035)$, and increased birth weight $(P=.005)$ (Table 4$)$.

\section{Discussion}

This was a multi-center cross-sectional study conducted in three tertiary university hospitals in Shanghai, China. We found that intrapartum medical interventions become common obstetric practices in urban China. Also multifactorial variables associated with duration of labour were identified in our study.

It was found in this study that the intrapartum interventions accounted for $27.4 \%$ in amniotomy, $37.9 \%$ in

Table 4 Multivariable linear regression of factors associated with duration of total stage of labour

\begin{tabular}{lllll}
\hline Variables & $\beta^{\mathrm{a}}$ & $95 \% \mathrm{Cl}$ & $t$ Test & $P$ value \\
\hline Age & 0.01 & $(-0.01,0.02)$ & 0.98 & 0.328 \\
Epidural analgesia $^{\mathrm{b}}$ & 0.85 & $(0.73,0.96)$ & 15.63 & $<0.001$ \\
Parity $^{\mathrm{c}}$ & -0.54 & $(-0.62,-0.37)$ & -7.84 & $<0.001$ \\
Continuous EFM $^{\mathrm{b}}$ & 0.12 & $(0.02,0.23)$ & 2.11 & 0.035 \\
Amniotomy $^{\mathrm{b}}$ & 0.09 & $(-0.03,0.21)$ & 1.49 & 0.136 \\
Birth weight & 0.20 & $(0.06,0.34)$ & 2.81 & 0.005
\end{tabular}

EFM Electronic fetal monitoring; Cl Confidence interval;

${ }^{a}$ Due to skewness of the distribution of labour duration, data was ztransformed before analysed using multivariable linear regression; ${ }^{\mathrm{b}}$ Binary variable (yes $=1, \mathrm{no}=0$ ); ${ }^{c}$ Binary variable (nullipara $=0$, multipara $=1$ ) oxytocin administration, and $53.0 \%$ in the use of continuous EFM (Table 3), unfolding that these procedures are common interventional practices in China's obstetric settings. Meanwhile, we found in our study that the overall epidural rate was $52.9 \%$, whereas an Australian study reported that the overall rate of epidural analgesia was $35.9 \%$ [31]. Beyond that, our study showed that the rate of ICS was $18.7 \%$. This rate is lower than Lumbiganon et al.'s report of $24.2 \%$ in China [22], but still much higher than Bernitz et al.'s report of 5.9-6.8\% in Norway [23]. Our findings illustrated a technocratic model of care for normal childbirth in China, which could be explained by the fact that China's maternity care is an facility based obstetrician-led model [32-34]. The regulations and organisational framework of maternity services constitute contextual factors fostering medical interventions during labour [35].

We found in our study that compared with nulliparas, multiparas were less likely to receive intrapartum interventions including amniotomy, oxytocin, continuous EFM, and epidural analgesia (Table 3). Similar findings have been previously reported by Grylka-Baeschlin et al.'s study, where there were lower intervention rates in multiparas than in primiparas [36]. For neonatal birth weight, we found no statistically significant differences between the nulliparas group and the multiparas group, which indicated that parity did not affect this variable 
significantly. Admittedly, further studies still need to be conducted on account of the causality challenge of this study. Meanwhile, our study also identified the independent multifactorial variables associated with labour duration, ranging from epidural analgesia, parity, continuous EFM, and birth weight (Table 4) .

Firstly, by adjusting for confounding, we found an association between labour duration and epidural analgesia. Our study indicated that use of epidural was associated with longer duration of labour. This finding was in concordance with Turner et al.'s findings [31]. Although epidurals may reduce pain during labour more effectively than any other form of pain relief, it may also be associated with unwanted effects like prolonged labour, hypotension, drowsiness and fever [37]. Therefore, to ensure a positive childbirth experience, women should be allowed to make decisions about their pain management. Epidural analgesia can be one of the options to choose when required by labouring women [5]. Beyond that, nonpharmacologic methods such as some relaxation therapies and continuous labour support should also be offered to women, in order to help them feel more in control and satisfied with their labours [38].

Secondly, the results of our study demonstrated that labour duration was significantly longer in nulliparous women than that in multiparous women, which was consistent with Chen et al.'s finding [39]. Concurrently, durations of the first, second, and total stage of labour in our study was similar to those reported by Chen et al. [39]. Then we found that parity was an independent variable associated with labour duration.

In addition, we found an association between continuous EFM and duration of labour. On the one hand, continuous EFM might restrict women from moving freely during labour and could be associated with prolonged labour. Previous studies demonstrated that freedom to move and adopt upright positions in labour results in a range of physical and psychological benefits for women, including reduced risk of caesarean section, increased sense of control during labour and increased satisfaction with the birth experience [40]. Therefore, women should be encouraged to be mobile and to adopt comfortable positions of their choice so as to gain a positive childbirth experience. On the other hand, continuous EFM might be performed for labouring women because of prolonged labour. Therefore, temporal direction of the association between continuous EFM and duration of labour could not be clearly ascertained.

Furthermore, we found in our study that increased birth weight was an independent factor associated with longer duration of labour, which is consistent with Leftwich et al.'s study conducted in the US [41]. Based on this research evidence, it is reasonable to allow longer time for labour progression when a larger fetus is suspected [41]. Beyond that, this finding also highlighted the importance to design and implement weight management interventions that may prompt women to conceive an appropriate size of fetus and to experience a normal labour progression.

However, it is notable that we did not find any association between duration of labour and amniotomy (Table 4). It can be assumed that amniotomy might be performed for women who had presented a prolonged labour but labour was not prolonged due to amniotomy. Interestingly, however, Vadivelu et al. have shown that amniotomy was associated with a shorter labour duration compared with conservative management in women with singleton pregnancies [42]. Conversely, Chen et al. found that in nulliparas, the average time of first stage of labour and total labour duration increased due to amniotomy [39]. The association between amniotomy and labour duration varied due to different research designs and inter-study heterogeneity. Yet Chen et al.'s study illustrated that women with medical interventions were more likely to have prolonged labour processes [39]. And there is no evidence that these interventions can improve childbirth experience for women who have had a prolonged labour [43]. Therefore, amniotomy, as one of the most common interventions in modern obstetric practice, should be performed with caution instead of being used routinely during labour management.

Meanwhile, we found in our study that maternal age was not associated with duration of labour (Table 4). However, this does not mean that the variable of age is unrelated to labour duration and management of labour. Greenberg et al. stated that older women had a persistently higher likelihood of experiencing longer labour and prolonged labour than younger women [44]. Given these contradictory findings, further research is needed to clarify the association between maternal age and duration of labour.

From all discussed above, we can see in this study that various medical interventions prevail in Chinese urban obstetric settings. In concordance with our findings, previous studies have also noted that there is a continually increasing trend in routine use of medico-technical interventions $[17,45,46]$. Lu et al. also pointed out the current situation of frequently used intrapartum interventions which may substantially distort the labour pattern [47]. According to International Confederation of Midwives (ICM), midwives are the most appropriate care providers to attend childbearing women [48]. One Cochrane Review by Sandall et al. suggests that women who received midwife-led continuity models of care were less likely to experience intervention and more likely to be satisfied with their care than women who received other models of care [49]. As such, models of care with lower intervention rates such as midwife-led models of care should be developed and implemented in order to rectify the medicalisation of childbirth in China. 


\section{Limitations}

One of the limitations of our study is the causality difficulty of ascertaining the association between duration of labour and the several explanatory variables due to the cross-sectional nature of our collected data. Meanwhile, we did not address all the possible predictive factors that could affect women's labour duration, though we had attempted to control some of the identifiable confounders. Another limitation is that our study only included women with vertex presentation, term birth, and spontaneous onset of labour, thus limiting its generalizability and applicability to other women who were excluded. In this study, women's cervical dilatation was assessed by digital vaginal examination, which was subjective and might cause some unavoidable measurement errors. In spite of these limitations, the strengths of our study include the fact that women's clinical data were collected through medical charts prospectively, from women's onset of labour till completion of delivery. As such, the information bias is considered to be minimal.

\section{Conclusion}

Currently in urban China, intrapartum interventions for childbearing women mainly consist of various medico-technical measures during labour. Among them, continuous EFM, amniotomy, and oxytocin treatment have become common practices. Also, the magnitude of epidural analgesia in our study represented a higher proportion among labouring women, indicating that women in urban China are on the one hand having more choices of and access to labour analgesia services, and on the other hand are receiving more pharmacologic methods for labour pain management. Meanwhile, epidural analgesia, primiparity, continuous EFM, and increased birth weight are associated with longer duration of labour. Further research is required to validate these variables and to determine the modifiable factors for labour management. In order to limit unnecessary intrapartum medical interventions and to improve womens' childbirth experience, obstetric care providers should take full account of these factors during prenatal counseling and in the process of labour management for childbearing women. Furthermore, there is an urgent need for developing models of care with lower intervention rates such as midwife-led models of care to rectify the medicalisation of childbirth in China.

\section{Supplementary information}

Supplementary information accompanies this paper at https://doi.org/10. 1186/s12884-020-03072-x.

Additional file 1. Questionnaire

\begin{abstract}
Abbreviations
BMl: Body mass index; Cl: Confidence interval; CNY: Chinese yuan;

EFM: Electronic fetal monitoring; GWG: Gestational weight gain;

ICM: International confederation of midwives; ICS: Intrapartum caesarean section; SOL: Stage of labour; WHO: World health organization
\end{abstract}

\section{Acknowledgements}

We would like to extend our thanks to Obstetrics and Gynecology Hospital of Fudan University, Shanghai Pudong Hospital of Fudan University, and Huashan Hospital North of Fudan University, for allowing us to conduct this study. We would sincerely like to acknowledge the help of all supervisors and data collectors of this study, as well as the study participants for their continuous cooperation and support.

\section{Authors' contributions}

Involved in the design and coordination: CYG, XQ. Participated in analysis: XJW, ZJZ. Participated in interpretation of data: CYG, CXZ, ZZ. Prepared the draft: CYG, XQ. Revised drafts of the paper: CYG, SS. All authors contributed to drafting and finalizing the manuscript. All authors read and approved the final manuscript.

\section{Funding}

This work was supported by School of Nursing, Fudan University, Shanghai, China (Grant Number FNF201703). However, it had no role in the design of the study, collection, analysis, interpretation of data, and in writing the manuscript.

\section{Availability of data and materials}

The datasets used and/or analyzed during the current study are available from the corresponding author on reasonable request.

\section{Ethics approval and consent to participate}

Ethical approval was received from the Hospital Ethics Committee (OGHEC2017-65). Access to undertake the study was given by the head of the labour and delivery units of the three hospitals where participants were to be recruited. Study purposes were stated to obtain their permissions of this study. All potential participants were recruited from the labour and delivery unit and provided written information on the study before signed consent was obtained. Participation in the study was voluntary and refusal to respond to specific questions or interruption from the study was allowed at any time during the labour process. All the information obtained from the participants remained confidential and anonymous. In addition, the dissemination of the study findings does not refer specific objects but the general source population.

\section{Consent for publication \\ Not applicable.}

\section{Competing interests}

The authors declare that they have no competing interests.

\section{Author details}

${ }^{1}$ Department of Maternal, Child and Adolescent Health, School of Public Health, Fudan University, Shanghai, China. ${ }^{2}$ Department of Nursing, Obstetrics \& Gynaecology Hospital of Fudan University, Shanghai, China. ${ }^{3}$ Department of Epidemiology, School of Public Health, Fudan University, Shanghai, China. ${ }^{4}$ Department of Women and Children's Health,

Reproductive Health, Karolinska Institutet, Stockholm, Sweden. ${ }^{5} \mathrm{Global}$ Health Institute, Fudan University, Shanghai, China.

Received: 25 February 2020 Accepted: 19 June 2020

Published online: 27 July 2020

\section{References}

1. World Health Organization. Care in Normal Birth: a practical guide. Birth 1997;24(2):121-3.

2. Cavallaro FL, Cresswell JA, França GV, Victora CG, Barros AJ, Ronsmans C. Trends in caesarean delivery by kcountry and wealth quintile: crosssectional surveys in southern Asia and sub-Saharan Africa. Bull World Health Organ. 2013;91(12):914-22D. 
3. Clesse C, Lighezzolo-Alnot J, de Lavergne S, Hamlin S, Scheffler M. The evolution of birth medicalisation: a systematic review. Midwifery. 2018;66: 161-7.

4. Çalik KY, Karabulutlu Ö, Yavuz C. First do no harm - interventions during labor and maternal satisfaction. BMC Pregnancy Childbirth. 2018;18(1):415.

5. World Health Organization. WHO recommendations: Intrapartum care for positive childbirth experience.https://apps.who.int/iris/bitstream/handle/1 0665/260178/9789241550215-eng.pdf?sequence=1\&isAllowed=y . Accessed 4 Nov 2019. (2018).

6. Davis-Floyd R. The technocratic, humanistic, and holistic paradigms of childbirth. Int J Gynaecol Obstet. 2001;75(Suppl 1):S5-23.

7. Miller S, Abalos E, Chamillard M, Ciapponi A, Colaci D, Comandé D, et al. Beyond too little, too late and too much, too soon: a pathway towards evidence-based, respectful maternity care worldwide. Lancet. 2016; 388(10056):2176-92

8. Alfirevic Z, Devane D, Gyte GM, Cuthbert A. Continuous cardiotocography (CTG) as a form of electronic fetal monitoring (EFM) for fetal assessment during labor. Cochrane Database Syst Rev. 2017;2:CD006066.

9. Jiang H, Qian X, Carroli G, Garner P. Selective versus routine use of episiotomy for vaginal birth. Cochrane Database Syst Rev. 2017;2:CD000081.

10. Gibbons L, Belizán JM, Ja L, Betrán AP, Merialdi M, Althabe F. The Global numbers and costs of additionally needed and unnecessary Caesarean sections performed per year: Overuse as a Barrier to universal coverage. World Heal Rep Backgr Pap. 2010;30:1-31.

11. Seijmonsbergen-Schermers AE, Zondag DC, Nieuwenhuijze M, Van den Akker T, Verhoeven CJ, Geerts C, et al. Regional variations in childbirth interventions in the Netherlands: a nationwide explorative study. BMC Pregnancy Childbirth. 2018;18(1):192.

12. World Health Organization. WHO statement on caesarean section rates. BJOG. 2016;123(5):667-70.

13. Hellerstein S, Feldman S, Duan T. China's $50 \%$ caesarean delivery rate: is it too high? BJOG. 2015;122(2):160-4.

14. Mazzoni A, Althabe F, Liu NH, Bonotti AM, Gibbons L, Sánchez AJ, et al. Women's preference for caesarean section: a systematic review and metaanalysis of observational studies. BJOG. 2011;118(4):391-9.

15. The American College of Obstetricians and Gynecologists. ACOG Committee Opinion No. 766 summary: approaches to limit intervention during labor and birth. Obstet Gynecol. 2019;133(2):406-8.

16. Petersen A, Poetter U, Michelsen C, Gross MM. The sequence of intrapartum interventions: a descriptive approach to the cascade of interventions. Arch Gynecol Obstet. 2013;288(2):245-54.

17. Nyman V, Roshani L, Berg M, Bondas T, Downe S, Dencker A. Routine interventions in childbirth before and after initiation of an action research project. Sex Reprod Healthc. 2017;11:86-90.

18. Bohren MA, Mehrtash H, Fawole B, Maung TM, Balde MD, Maya E, et al. How women are treated during facility-based childbirth in four countries: a cross-sectional study with labour observations and community-based surveys. Lancet. 2019;394(10210):1750-63.

19. Thomson G, Feeley C, Moran VH, Downe S, Oladapo OT. Women's experiences of pharmacological and non-pharmacological pain relief methods for labor and childbirth: a qualitative systematic review. Reprod Health. 2019;16(1):71

20. Li HT, Luo S, Trasande L, Hellerstein S, Kang C, Li JX, et al. Geographic variations and temporal trends in cesarean delivery rates in China, 20082014. JAMA. 2017:317(1):69-76.

21. Moore B. Appropriate technology for birth. Lancet. 1985;2(8452):436-7.

22. Lumbiganon P, Laopaiboon M, Gülmezoglu AM, Souza JP, Taneepanichskul S, Ruyan P, et al. Method of delivery and pregnancy outcomes in Asia: the WHO global survey on maternal and perinatal health 2007-08. Lancet. 2010; 375(9713):490-9.

23. Bernitz S, Dalbye R, Zhang J, Eggebø TM, Frøslie KF, Olsen IC, et al. The frequency of intrapartum caesarean section use with the WHO partograph versus Zhang's guideline in the labor progression study (LaPS): a multicentre, cluster-randomised controlled trial. Lancet. 2019;393(10169): 340-8.

24. Li PC, Liao ZJ, Wang C, Zhou YB, Li HT, Chen DJ, et al. Maternalcharacteristics and birth outcomes under different family planning policy. Chin J Reprod Health. 2017;28(6):501-5.

25. Wang JM. Discussion on obstetric development mode of tertiary general hospital from treatment status of high risk pregnancy. Med Philo. 2017;38(6): $91-4$
26. Zhang J, Landy HJ, Branch DW, Burkman R, Haberman S, Gregory KD, et al. Contemporary patterns of spontaneous labor with normal neonatal outcomes. Obstet Gynecol. 2010;116(6):1281-7.

27. Huang YQ. Clinical epidemiology. People's Medical Publishing House, 2017; $4^{\text {th }}$ edition.

28. Lee L, Dy J, Azzam H. Management of Spontaneous Labour at term in healthy women. J Obstet Gynaecol Can. 2016;38(9):843-65.

29. Hanley GE, Munro S, Greyson D, Gross MM, Hundley V, Spiby H, et al. Diagnosing onset of labor: a systematic review of definitions in the research literature. BMC Pregnancy Childbirth. 2016;16:71.

30. Institute of Medicine. Weight gain during pregnancy: reexamining the guidelines. Washington, DC: National Academies Press; 2009.

31. Turner J, Flatley C, Kumar S. Epidural use in labor is not associated with an increased risk of maternal or neonatal morbidity when the second stage is prolonged. Aust N Z J Obstet Gynecol. 2020;60:336-43.

32. Liang J, Mu Y, Li X, Tang W, Wang Y, Liu Z, et al. Relaxation of the one child policy and trends in caesarean section rates and birth outcomes in China between 2012 and 2016: observational study of nearly seven million health facility births. BMJ. 2018;360:k817.

33. Gao Y, Zhou H, Singh NS, Powell-Jackson T, Nash S, Yang M, et al. Progress and challenges in maternal health in western China: a countdown to 2015 national case study. Lancet Glob Health. 2017;5(5):e523-36.

34. Feng $X L, X u L$, Guo Y, Ronsmans $C$. Factors influencing rising caesarean section rates in China between 1988 and 2008. Bull World Health Organ. 2012;90(1):30-9 39A.

35. Pazandeh F, Potrata B, Huss R, Hirst J, House A. Women's experiences of routine care during labour and childbirth and the inflfluence of medicalisation: a qualitative study from Iran. Midwifery. 2017;53:63-70.

36. Grylka-Baeschlin S, Petersen A, Karch A, Gross MM. Labour duration and timing of interventions in women planning vaginal birth after caesarean section. Midwifery. 2016;34:221-9.

37. Anim-Somuah M, Smyth RM, Cyna AM, Cuthbert A. Epidural versus nonepidural or no analgesia for pain management in labor. Cochrane Database Syst Rev. 2018:5:CD000331.

38. Smith CA, Levett KM, Collins CT, Crowther CA. Relaxation techniques for pain management in labor. Cochrane Database Syst Rev. 2011;12:CD009514.

39. Chen H, Cao L, Cao W, Wang H, Zhu C, Zhou R. Factors affecting labor duration in Chinese pregnant women. Medicine (Baltimore). 2018;97(52): e13901.

40. Lawrence A, Lewis L, Hofmeyr GJ, Styles C. Maternal positions and mobility during first stage labor. Cochrane Database Syst Rev. 2013;8:CD003934.

41. Leftwich HK, Gao W, Wilkins I. Does increase in birth weight change the normal labor curve? Am J Perinatol. 2015;32(1):87-92.

42. Vadivelu M, Rathore S, Benjamin SJ, Abraham A, Belavendra A, Mathews JE. Randomized controlled trial of the effect of amniotomy on the duration of spontaneous labor. Int J Gynaecol Obstet. 2017;138(2):152-7.

43. Smyth RM, Markham C, Dowswell T. Amniotomy for shortening spontaneous labor. Cochrane Database Syst Rev. 2013;6:CD006167.

44. Greenberg MB, Cheng YW, Sullivan M, Norton ME, Hopkins LM, Caughey AB. Does length of labor vary by maternal age? Am J Obstet Gynecol. 2007; 197(4):428.e1-7.

45. Begley CM. Intervention or interference? The need for expectant care throughout normal labor. Sex Reprod Healthc. 2014;5(4):160-4.

46. Scamell M, Alaszewski A. Fateful moments and the categorisation of risk: midwifery practice and the ever-narrowing window of normality during childbirth. Health Risk Soc. 2012;14(2):207-21.

47. Lu D, Zhang L, Duan T, Zhang J. Labor patterns in Asian American women with vaginal birth and normal perinatal outcomes. Birth. 2019;46(4):608-15.

48. International Confederation of Midwives. Philosophy and Model of Midwifery Care. https://www.internationalmidwives.org/assets/files/ definitions-files/2018/06/eng-philosophy-and-model-of-midwifery-care.pdf Accessed 15 Jan 2020. (2014)

49. Sandall J, Soltani H, Gates S, Shennan A, Devane D. Midwife-led continuity models versus other models of care for childbearing women. Cochrane Database Syst Rev. 2016;4:CD004667.

\section{Publisher's Note}

Springer Nature remains neutral with regard to jurisdictional claims in published maps and institutional affiliations. 